\title{
Importance of patient-reported outcomes and health-related quality of life when considering prostate cancer treatment
}

\author{
James HL Tsu *, FRCS(Urol), FHKAM (Surgery) \\ Division of Urology, Department of Surgery, The University of Hong Kong, Queen Mary Hospital, Pokfulam, Hong Kong
}

*Corresponding author: thl589@ha.org.hk

Hong Kong Med J 2020;26:88-9

https://doi.org/10.12809/hkmj205095

Prostate cancer is the third commonest cancer among men in Hong Kong. ${ }^{1}$ For organ-confined disease the current treatment options include surgical extirpation, external beam radiotherapy, brachytherapy, novel ablative therapy and active surveillance, each with different advantages and shortcomings. Therefore, patients often find difficulty navigating through the algorithm of treatment decision, even with advice from urologists and oncologists. Take the two classic options, surgery and radiotherapy as an example; each has comparable oncological outcome but is associated with a set of different possible complications, some of which may be long-lasting to the patient. ${ }^{2,3}$ In this regards, data on health-related quality of life (HrQoL) and patient-reported outcome (PRO) become important factors to take into consideration when choosing a prostate cancer treatment.

Health-related QoL has been defined as the functional effect of an illness and its consequent therapy upon a patient, as perceived by patient. ${ }^{4}$ Instruments used to assess HrQoL represent a much broader categoryofhealth status measures collectively referred to as PRO measures that are directly elicited from the patient. ${ }^{5,6}$ These PRO measures can be used to assess a unidimensional variable such as a symptom, or a multidimensional concept such as HrQoL, and are either self-administered or administered by a trained interviewer. Because they are derived from the patient's perspective, data from PRO measures are increasingly recognised to be as important as traditional physician-measured clinical outcomes. ${ }^{7}$ This is particularly important in prostate cancer management when subjective functional outcomes such as erectile function and urinary continence are often regarded as important as oncological control. After treatment, prostate cancer patients have subjectively lower HrQoL than their healthy peers in the general population ${ }^{8}$ and functional outcomes are often under-reported by physicians. ${ }^{9,10}$ Therefore, studies such as the one by $\mathrm{Ng}$ et al in this issue of Hong Kong Medical Journal provide a welcome guide for patients and clinicians in the choice of prostate cancer treatments. ${ }^{11}$

$\mathrm{Ng}$ et $\mathrm{al}^{11}$ report a retrospective study of the early and intermediate functional outcomes of a group of patients who underwent two prostate cancer treatments (radical prostatectomy and radical radiotherapy), as measured by hospital record review and the Chinese version of the Expanded Prostate Index Composite (EPIC). The EPIC measures PRO in urinary, bowel and sexual domains and in each gives a summary $\mathrm{HrQoL}$ score. Common to most studies worldwide, it noted that radical surgery resulted in significantly worse urinary incontinence PRO than radiotherapy and this difference remained significant over time.,12,13 Contrary to published data, sexual function PRO was similar between the two groups but this was likely related to the use of androgen deprivation in the radiotherapy group. ${ }^{2,13}$ Overall, patients treated surgically had a poorer urinary but similar bowel and sexual HrQoL to patients treated with radiotherapy. Although numerous studies have been published before comparing the PRO and HrQoL after different prostate cancer treatment modalities in Asian patients, including Japanese and Chinese patients, the current study is the first of its kind in Hong Kong. ${ }^{14-20}$ Valuable reference can be taken from its findings when discussing prostate cancer management in the local setting. A particular merit of the study is the fact that all patients in the surgical group were treated with a single contemporary approach (robot-assisted radical prostatectomy), a practice nowadays almost universally adopted in all urological units with the access to a surgical robot. Similarly, since the radiotherapy group patients was chosen from a relatively short time frame, the techniques of radiotherapy were unlikely to be changed, resulting in a uniform cohort.

Some caution needs to be exercised when interpreting the data. Initial post-treatment functional outcomes in the study were not patientreported but were measured by clinicians and this has been acknowledged as a limitation by the authors. Second, the strategy of intraoperative cavernosal nerve-sparing techniques during the radical prostatectomy procedure was not included. Whether nerve-sparing strategies were adopted will affect the sexual PRO subsequently reported. Third, information about the adjunctive use of treatment to ameliorate the functional deficit (eg, 
phosphodiesterase-5 inhibitors or intracorporeal prostaglandins for erectile dysfunction, additional surgical procedure for post-prostatectomy urinary incontinence) was not presented. These may profoundly affect the PRO of this group of patients.

Further studies to prospectively assess the PRO of patients with prostate cancer at different time points after their treatment should be conducted to give our patients the best data to guide their choice of treatment. Information about measures to preserve or re-achieve erectile function and urinary continence should be carefully recorded.

\section{Author contributions}

The author has approved the final version for publication, and takes responsibility for its accuracy and integrity.

\section{Conflict of interest}

The author declares no conflict of interest.

\section{References}

1. Hong Kong Cancer Registry. Hong Kong Cancer Statistics 2017. Available from: https:/www3.ha.org.hk/cancereg/ pdf/overview/Summary\%20of\%20CanStat\%202017.pdf. Accessed 21 Mar 2020.

2. Hamdy FC, Donovan JL, Lane JA, et al. 10-Year outcomes after monitoring, surgery, or radiotherapy for localized prostate cancer. N Engl J Med 2016;375:1415-24.

3. Chen RC, Basak R, Meyer AM, et al. Association between choice of radical prostatectomy, external beam radiotherapy, brachytherapy, or active surveillance and patient-reported quality of life among men with localized prostate cancer. JAMA 2017;317:1141-50.

4. Schipper H, Clinch J, Powell V. Definitions and conceptual issues. In: Spilker B, editor. Quality of Life Assessments in Clinical Trials. New York: Raven Press; 1990: 11-24.

5. US Food and Drug Administration. Guidance for industry patient-reported outcome measures: use in medical product development to support labeling claims. Draft Guidance. 2006. Available from: https://www.fda.gov/ media/77832/download. Accessed 21 Mar 2020.

6. Doward LC, McKenna SP. Defining patient-reported outcomes. Value Health 2004;7 Suppl 1:S4-8.

7. Meadows KA. Patient-reported outcome measures: an overview. Br J Community Nurs 2011;16:146-51.

8. Choi EP, Wong CK, Tsu JH, et al. Health-related quality of life of Chinese patients with prostate cancer in comparison to general population and other cancer populations. Support Care Cancer 2016;24:1849-56.

9. Di Maio M, Gallo C, Leighl NB, et al. Symptomatic toxicities experienced during anticancer treatment: agreement between patient and physician reporting in three randomized trials. J Clin Oncol 2015;33:910-5.

10. Fromme EK, Eilers KM, Mori M, Hsieh YC, Beer TM. How accurate is clinician reporting of chemotherapy adverse effects? A comparison with patient-reported symptoms from the Quality-of-Life Questionnaire C30. J Clin Oncol 2004;22:3485-90.

11. Ng CF, Kong KY, Li CY, et al. Patient-reported outcomes after surgery or radiotherapy for localised prostate cancer: a retrospective study. Hong Kong Med J 2020;95-101.

12. Donovan JL, Hamdy FC, Lane JA, et al. Patient-reported outcomes after monitoring, surgery, or radiotherapy for prostate cancer. N Engl J Med 2016;375:1425-37.

13. Barocas DA, Alvarez J, Resnick MJ, et al. Association between radiation therapy, surgery, or observation for localized prostate cancer and patient-reported outcomes after 3 years. JAMA 2017;317:1126-40.

14. Hashine K, Kusuhara Y, Miura N, Shirato A, Sumiyoshi Y, Kataoka M. Health-related quality of life using SF-8 and EPIC questionnaires after treatment with radical retropubic prostatectomy and permanent prostate brachytherapy. Jpn J Clin Oncol 2009;39:502-8.

15. Jo Y, Junichi H, Tomohiro F, Yoshinari I, Masato F. Radical prostatectomy versus high-dose rate brachytherapy for prostate cancer: effects on health-related quality of life. BJU Int 2005;96:43-7.

16. Kakehi Y, Takegami M, Suzukamo Y, et al. Health related quality of life in Japanese men with localized prostate cancer treated with current multiple modalities assessed by a newly developed Japanese version of the Expanded Prostate Cancer Index Composite. J Urol 2007;177:185661.

17. Miwa S, Mizokami A, Konaka $\mathrm{H}$, et al. Prospective longitudinal comparative study of health-related quality of life and treatment satisfaction in patients treated with hormone therapy, radical retropubic prostatectomy, and high or low dose rate brachytherapy for prostate cancer. Prostate Int 2013;1:117-24.

18. Namiki S, Takegami M, Kakehi Y, Suzukamo Y, Fukuhara S, Arai Y. Analysis linking UCLA PCI with Expanded Prostate Cancer Index Composite: an evaluation of health related quality of life in Japanese men with localized prostate cancer. J Urol 2007;178:473-7.

19. Ueno S, Kitagawa $Y$, Onozawa $M$, et al. Background factors and short-term health-related quality of life in patients who initially underwent radical prostatectomy or androgen deprivation therapy for localized prostate cancer in a Japanese prospective observational study ( $\mathrm{J}-\mathrm{CaP}$ Innovative Study-1). Prostate Int 2018;6:7-11.

20. Zhang K, Gong K, Zhou LQ, Na YQ. Quality of life among patients with advanced prostate cancer: a survey using functional assessment of cancer therapy-prostate in China [in Chinese]. Zhonghua Yi Xue Za Zhi 2008;88:665-8. 